\title{
Trapping of Payne rearrangement intermediates with arylselenide anions
}

\author{
Michael E. Jung* and Daniel L. Sun \\ Department of Chemistry and Biochemistry, University of California, Los Angeles, CA 90095-1569, United States
}

\section{ARTICLE INFO ABSTRACT}

Article history:

Received

Received in revised form

Accepted

Available online
The intermediate epoxy alcohols prepared via a Payne rearrangement can be trapped with arylselenide anions, giving mixtures of ring-opened products. The 1-arylseleno-2,3-diols are generally favored over the 3-arylseleno-1,2-diols in this process although the reaction of trisubstituted epoxyalcohols, e.g., 17, differs from those of disubstituted epoxyalcohols, e.g., 21.

\section{Keywords:}

Epoxy alcohol opening

Aryl selenide anions

Payne rearrangement

Arylseleno diols

Several years ago we reported the rearrangement of epoxy alcohols and their silyl ethers using silyl triflates to produce silylprotected aldol products in a process we termed the "non-aldol aldol". Although the epoxy alcohols $\mathbf{2}$ prepared using a Sharpless asymmetric epoxidation of the $E$ 2-methyl allylic alcohols $\mathbf{1}$ gave very good yields of the aldol products $\mathbf{3}$, the reaction of the epoxides $\mathbf{5}$ derived from the corresponding $Z$ allylic alcohols $\mathbf{4}$ could be problematic due presumably to steric hindrance to the desired rearrangement, although conditions were found to produce the anti aldol products 6 (Scheme 1). ${ }^{2} \mathrm{We}$ wondered whether a longer sequence involving a double inversion process might allow us to obtain the anti aldol products $\mathbf{1 0}$ from the $E$ epoxy alcohols 2 (Scheme 2). This would involve the trapping of the Payne rearrangement ${ }^{3}$ equilibrium of $\mathbf{2}$ and $\mathbf{7}$<smiles>[R]C=C(C)CO</smiles>

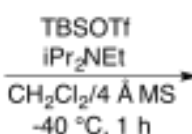<smiles>[R]C(O[Sb])[C@@H](C)C=O</smiles><smiles>[R]C=C(C)CO</smiles><smiles>[R]C1O[C@@]1(C)CO</smiles>

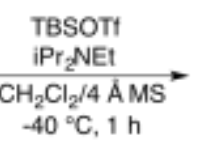

3 OTBS<smiles>[R]C(C)C(C)C=O</smiles>

6

Scheme 1. Non-aldol aldol reaction to give 3 and $\mathbf{6}$. with a strong nucleophile to give $\mathbf{8}$, followed by selective protection of the secondary alcohol and cyclization to the terminal epoxide 9 and then final Yamamoto rearrangement ${ }^{4}$ to give the anti aldol product 10. We report here our results of the trapping of the Payne rearrangement intermediates using aryl selenide anions.

* Corresponding author. E-mail address: jung@ chem.ucla.edu (M. E. Jung)

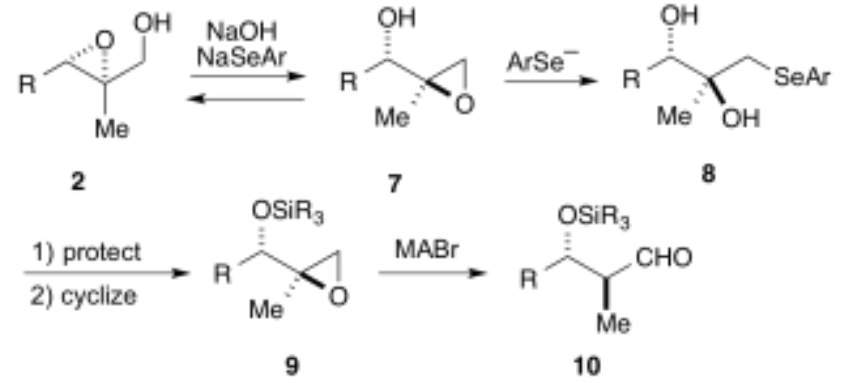

Scheme 2. Alternative route for anti aldol products $\mathbf{1 0}$.

In a beautiful approach to the synthesis of the alditols, ${ }^{5}$ Sharpless and Masamune reported the interception of one of the intermediates of the Payne rearrangement with thiolates to give selectively the 1-thiophenyl-2,3-diols (Scheme 3). Thus treatment of the epoxy alcohol $\mathbf{1 1}$ with thiophenol and aq. sodium hydroxide in dioxane afforded the product of selective opening of the intermediate rearranged epoxy alcohol $\mathbf{1 2}$ at the primary center to give predominately the product 13. Later Boeckman showed that this same process occurred with the methyl substituted epoxy alcohol $\mathbf{1 5}$ to give the diol $\mathbf{1 6}$ in an elegant synthesis of (-)-kromycin. ${ }^{6}$ We decided to study the analogous rearrangement using arylselenide anions instead of the phenylthiolates. Herein we report the results of that investigation. 
<smiles>OC[C@H]1O[C@@H]1COBr</smiles>
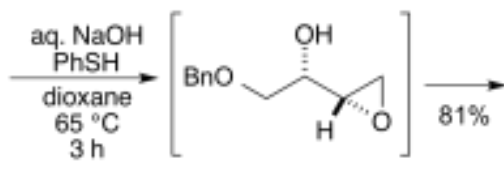

11<smiles>OC(COc1ccccc1)[C@H](O)Cc1ccccc1</smiles><smiles>OCC(O)C(COBr)Sc1ccccc1</smiles><smiles>CCC1OC1(C)CO</smiles>

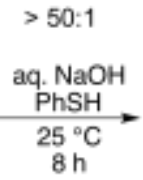

$88 \%$
14

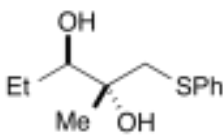

16
Scheme 3. Selective trapping of the Payne intermediate 12.

The epoxy alcohols were all prepared by an application of Sharpless asymmetric epoxidation ${ }^{7}$ of the readily available $E$ and $Z$-allylic alcohols. We decided to test one substrate in order to find the best conditions for the rearrangement-trapping process (Scheme 4) and therefore prepared the known epoxy alcohol $17 .^{1 \mathrm{a}}$

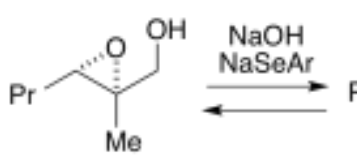

17<smiles>CCC(O)[C@@](C)(O)C[Se]Br</smiles>

19

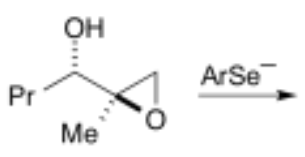

18<smiles>CCCC([Se])C(O)([Ge])CO</smiles>

$$
\mathrm{Ar}=\left(2,4,6-\mathrm{Me}_{3}\right) \mathrm{C}_{6} \mathrm{H}_{4}
$$

Scheme 4. Formation of the arylseleno diols.

Since the preference for opening the terminal epoxide $\mathbf{1 8}$ over the internal epoxide $\mathbf{1 7}$ is due to steric hindrance, we decided to use a very sterically hindered arylselenide. Thus the known bis(2,4,6trimethylphenyl) diselenide (dimesityl diselenide) ${ }^{8}$ was reduced with sodium borohydride to give the mesitylselenide anion. To a solution of the epoxy alcohol $\mathbf{1 7}$ in ethanol was added over 2 hours a solution of the sodium mesitylselenide and $1 \mathrm{M}$ (or $0.5 \mathrm{M}$ ) $\mathrm{NaOH}$. All of the reactions were stirred for 18 hours. The results (Table 1) showed that the temperature had a significant effect, namely higher temperatures generally gave more of the desired 1seleno-2,3-diol 19 than the product of direct opening, the 3seleno-1,2-diol 20 (entries a-d). ${ }^{9}$ Heating 17 with the selenide in ethanol at $85{ }^{\circ} \mathrm{C}$ (reflux) afforded the desired product in $48 \%$ yield along with $34 \%$ yield of the undesired product (entry d). Interestingly, adding all of the selenide and base at once seemed to improve the yield of the desired product (entry e vs entry b). However, higher temperatures in other solvents, e.g., $100{ }^{\circ} \mathrm{C}$ in isopropanol or aq. tert-butanol, gave much poorer results (entries $\mathrm{f}$ and $\mathrm{g}$ ). The ratio of desired to undesired product was best at

Table 1. Treatment of $\mathbf{1 7}$ with NaSeAr to give $\mathbf{1 9}$ and $\mathbf{2 0 .}$

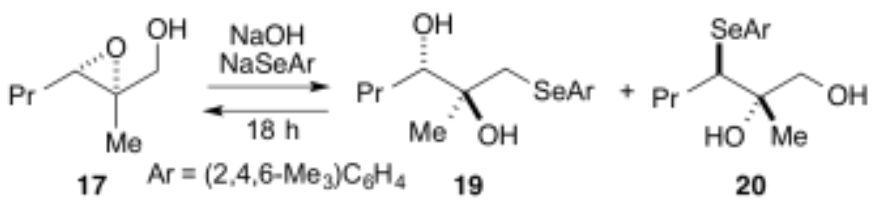

\begin{tabular}{cccccc}
\hline Entry & Solvent & Temp & $\mathbf{1 9}(\%)$ & $\mathbf{2 0}(\%)$ & $\begin{array}{c}\text { Overall } \\
\text { Yield (\%) }\end{array}$ \\
\hline $\mathrm{a}$ & $\mathrm{EtOH}$ & $0{ }^{\circ} \mathrm{C}$ & 13 & 45 & 58 \\
$\mathrm{~b}$ & $\mathrm{EtOH}$ & $22{ }^{\circ} \mathrm{C}$ & 31 & 53 & 84 \\
$\mathrm{c}$ & $\mathrm{EtOH}$ & $45{ }^{\circ} \mathrm{C}$ & 40 & 23 & 63 \\
$\mathrm{~d}$ & $\mathrm{EtOH}$ & $85{ }^{\circ} \mathrm{C}$ & 48 & 34 & 82 \\
$\mathrm{e}^{\mathrm{a}}$ & $\mathrm{EtOH}$ & $22{ }^{\circ} \mathrm{C}$ & 44 & 35 & 79 \\
$\mathrm{f}^{\mathrm{b}}$ & $\mathrm{iPrOH}$ & $100{ }^{\circ} \mathrm{C}$ & 30 & 13 & 43 \\
$\mathrm{~g}^{\mathrm{b}}$ & $\mathrm{aq} \mathrm{tBuOH}$ & $100{ }^{\circ} \mathrm{C}$ & 10 & 10 & 20
\end{tabular}

${ }^{\mathrm{a}}$ Added all at once. ${ }^{\mathrm{b}} 0.5 \mathrm{M} \mathrm{NaOH}$ was used.

$45^{\circ} \mathrm{C}(1.7: 1)$ but the overall yield was lower than that at $85{ }^{\circ} \mathrm{C}$ where the ratio was $1.4: 1$ (entries $\mathrm{c}$ and $\mathrm{d}$ ).

We next investigated the use of microwave heating for this process since some non-thermal effects have been observed especially in reactions of polar substrates. ${ }^{10}$ Thus the epoxy alcohol 17 was treated with the sodium mesitylselenide and $1 \mathrm{M}$ $\mathrm{NaOH}$ in ethanol at $22{ }^{\circ} \mathrm{C}$. The mixture was then placed in an industrial microwave oven and heated to the indicated temperatures for the time shown. The results (Table 2) indicated that these microwave conditions were favorable for the formation of the desired product $\mathbf{1 9}$ in preference to the undesired product 20. At all temperatures, shorter reaction times were better, presumably due to decomposition of the products on prolonged heating with base. Thus at $100{ }^{\circ} \mathrm{C}$, the shorter time of 12 hours was somewhat better than 48 hours, although the ratio was better at longer times (entries a and b). And at $85{ }^{\circ} \mathrm{C}$, heating for 12 hours afforded $60 \%$ of the desired product 19 along with $17 \%$ of the undesired 20, while heating for 48 hours gave only the desired product but in the lower yield of $41 \%$ (entries c and d). Finally we also investigated the use of heating in a sealed tube for an extended period. Thus heating an ethanolic solution of $\mathbf{1 7}$ at $80{ }^{\circ} \mathrm{C}$ in a sealed tube for 60 hours gave only the desired product 19 in an isolated yield of 56\%. The undesired product 20 seems to be selectively destroyed on prolonged heating. Therefore the best method for preparing the desired products was heating at $80-85{ }^{\circ} \mathrm{C}$ in ethanol, either via microwave or thermal heating.

Table 2. Reaction of $\mathbf{1 7}$ under microwave conditions to give compounds 19 and 20.

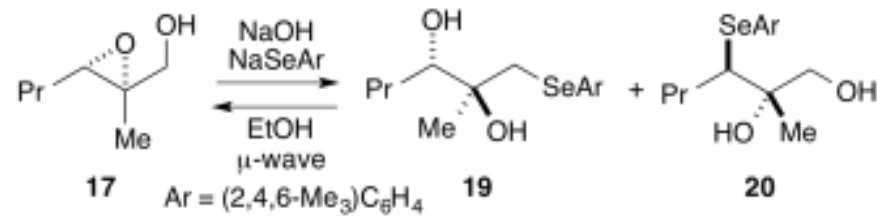

\begin{tabular}{cccccc} 
Entry & Time (h) & Temp & $\mathbf{1 9}(\%)$ & $\mathbf{2 0}(\%)$ & $\begin{array}{c}\text { Overall } \\
\text { Yield (\%) }\end{array}$ \\
\hline a & 48 & $100^{\circ} \mathrm{C}$ & 51 & 10 & 61 \\
$\mathrm{~b}$ & 12 & $100^{\circ} \mathrm{C}$ & 46 & 23 & 69 \\
$\mathrm{c}$ & 48 & $85^{\circ} \mathrm{C}$ & 41 & 0 & 41 \\
$\mathrm{~d}$ & 12 & $85^{\circ} \mathrm{C}$ & 60 & 17 & 77 \\
$\mathrm{e}^{\mathrm{a}}$ & 60 & $80^{\circ} \mathrm{C}$ & 56 & 0 & 56
\end{tabular}

${ }^{\mathrm{a}}$ Not microwave; sealed tube. 
Table 3. Reactions of disubstituted epoxy alcohols. ${ }^{\text {a }}$

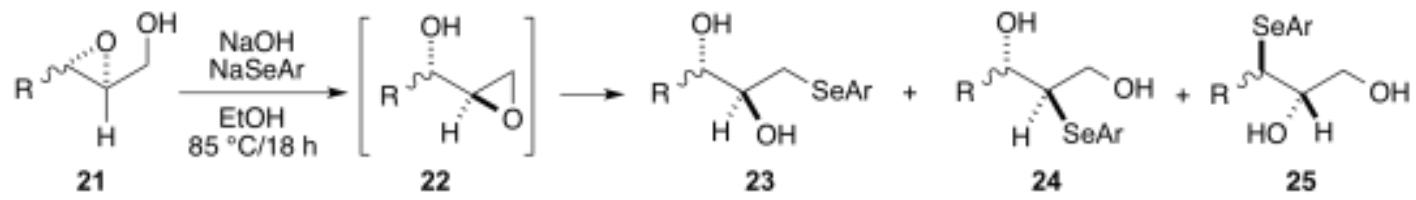

\begin{tabular}{|c|c|c|c|c|c|}
\hline Entry & Substrate & $\begin{array}{l}\text { Yield of 1-seleno- } \\
\text { 2,3-diol } \mathbf{2 3}(\%)\end{array}$ & $\begin{array}{l}\text { Yield of 2-seleno- } \\
\text { 1,3-diol } \mathbf{2 4}(\%)\end{array}$ & $\begin{array}{l}\text { Yield of 3-seleno- } \\
\text { 1,2-diol } \mathbf{2 5}(\%)\end{array}$ & Overall Yield (\%) \\
\hline $\mathrm{a}$ & & 39 & 0 & 46 & 85 \\
\hline $\mathrm{b}$ & $\mathrm{H}_{21} \mathrm{C}_{1 \mathrm{C}}$ & 24 & 51 & 24 & 99 \\
\hline $\mathrm{c}$ & & 42 & 27 & 30 & 99 \\
\hline $\mathrm{d}$ & & 28 & 29 & 36 & 93 \\
\hline $\mathrm{e}$ & & 65 & 29 & 0 & 94 \\
\hline $\mathrm{f}$ & & 53 & 40 & 0 & 93 \\
\hline $\mathrm{g}$ & & 52 & 24 & 0 & 76 \\
\hline
\end{tabular}

Using a series of disubstituted epoxides, we then looked at the substrate scope of the rearrangement-trapping process. In these substrates, three different products can be obtained, from opening at either end of the original epoxide $\mathbf{2 1}$, giving $\mathbf{2 4}$ and $\mathbf{2 5}$, or the terminal epoxide 22 giving 23 (Scheme 5). All of the epoxy alcohol substrates, 21a-g, were<smiles>[R]C1O[C@H]1CO</smiles>

21<smiles>[R]C(O)[C@H]1CO1</smiles>

22<smiles>[R9]C(O)C(O)C[Se]O</smiles>

23<smiles>OC[C@H](O)[C@H](O)[18OH]</smiles>

24<smiles></smiles>

25
Scheme 5. Rearrangement-trapping of the disubstituted epoxy alcohols 21 to give the three products 23-25.

prepared by known routes $^{5}$ using the Sharpless asymmetric epoxidation. Each was mixed with the sodium mesitylselenide and $1 \mathrm{M} \mathrm{NaOH}$ in ethanol and heated at $85{ }^{\circ} \mathrm{C}$ for 18 hours. The results (Table 3) indicate firstly that the overall yields for these substrates were excellent, generally greater than $90 \%$. Secondly, for these substrates not having the 2-methyl substituent, significant opening at $\mathrm{C} 2$ occurred to generate the 2-seleno-1,3diol 24. ${ }^{10}$ Thus the relatively unhindered substrates gave significant amounts of the 2 -seleno products (entries a-d) with relatively similar amounts of the 1 -seleno and 3 -seleno products, 23 and 25, respectively. When the attack of the hindered arylselenide anion at C-3 is made more difficult, due to the steric interaction of the acetonides, then no opening at C-3 is observed but only a mixture of the $\mathrm{C}-1$ and $\mathrm{C}-2$ products, 23 and $\mathbf{2 4}$. In these latter three cases (entries e-g), reasonable yields of the 1seleno product $\mathbf{2 3}$ could be isolated.

Since heating the mixture of the epoxy alcohols and the arylselenide anion in ethanol for longer periods of time seemed to give more of the desired 1-seleno product with respect to the 3seleno product (Table 2), we wondered if the formation of the selenodiols might well be reversible under these conditions. The product $\mathbf{2 0}$ formed by opening the starting epoxyalcohol $\mathbf{1 7}$ at $\mathrm{C}$ 3 might well be revert back to $\mathbf{1 7}$ via loss of the mesitylselenide anion before being converted via $\mathbf{1 8}$ into the desired product $\mathbf{1 9}$ (Scheme 6). Therefore we treated the isolated, pure 3-seleno-1,2diol 20 with sodium mesitylselenide and $1 \mathrm{M}$ sodium hydroxide 


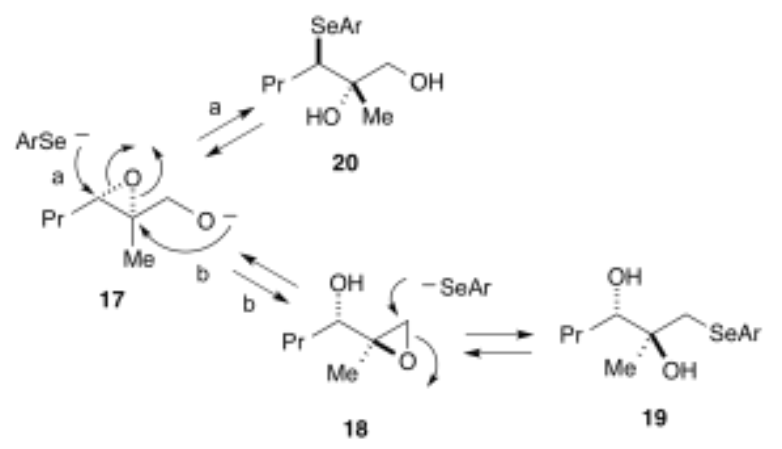

Scheme 6. Reversible formation of the selenodiols $\mathbf{1 9}$ and $\mathbf{2 0}$

in ethanol at $85{ }^{\circ} \mathrm{C}$ for 18 hours and isolated a mixture of the two products, the starting material in $74 \%$ yield and the rearranged product 19 in $23 \%$ isolated yield (Scheme 7). Thus the seleno diol 20 must lose the mesitylselenide anion and revert back to the epoxide 17, rearrange via Payne rearrangement to the isomeric epoxide 18, and then be opened at the terminal end of the epoxide 18 with the arylselenide anion to give 19. This implies that the formation of the products may be partially controlled by thermodynamic effects and not merely kinetic effects.

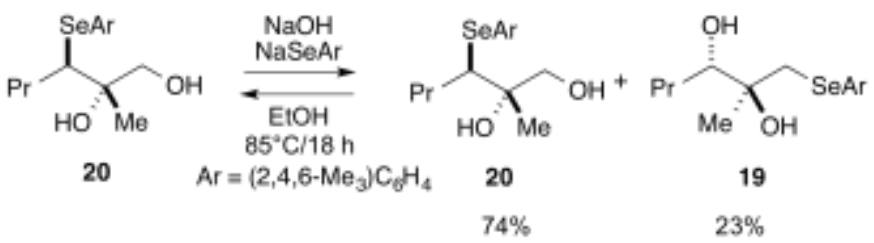

Scheme 7. Rearrangement-trapping of the disubstituted epoxy alcohols 21 to give the three products $\mathbf{2 3 - 2 5}$.

In conclusion, we have developed a useful method for the conversion of 1,2-epoxy alcohols to the corresponding 1-seleno2,3-diols using the hindered mesitylselenide anion under basic conditions in refluxing ethanol. The use of these compounds is under investigation and will be reported in due course.

\section{Acknowledgment}

This material is based upon work supported by the National Science Foundation under equipment grant no. CHE-1048804. We dedicate this publication to Harry Wasserman, a man of rare talent and grace.

\section{References and notes}

1. a) Jung, M. E.; D'Amico, D. C. J. Am. Chem. Soc. 1993, 115, 12208-12209. b) Jung, M. E.; D’Amico, D. C. J. Am. Chem. Soc. 1997, 119, 12150-12158. c) Jung, M. E.; Marquez, R. Tetrahedron Lett. 1999, 40, 3129-3132. d) Jung, M. E.; Hoffmann, B.; Rausch, B.; Contreras, J.-M. Org. Lett. 2003, 5, 3159-3161.

2. Jung, M. E.; Lee, W. S.; Sun, D. Org. Lett. 1999, 1, 307-309. The yields of the anti aldol products in these hindered cases were lower due to competing elimination to give the allylic bis(silyl ethers).

3. a) Payne, G. B. J. Org. Chem. 1962, 27, 3819-3822. b) Hanson, R. M. in Organic Reactions, Wiley, 2002, Vol. 60, Overman, L. E.; et al., Ed., 1-156. c) Wrobel, J. E.; Ganem, B. J. Org. Chem. 1983, 48, 3761-3769. (d) Jung, M. E.; van den Heuvel, A. Tetrahedron Lett. 2002, 43, 8169-8172.

4. a ) Ma r uoka, K.; Sa to, J.; Ya ma mot o, H. J. Am. Chem. Soc. 1991, 113, 5449-5450. b) Ma r u oka, K.; Sa t o, J.; Ya ma mot o, H. Tetrahedron 1992, 48, 3749-3762.

5. a) Katsuki, T.; Lee, A. W. M.; Ma, P.; Martin, S. V.; Masamune, S.; Sharpless, K. B.; Tuddenham, D.; Walker, F. J. J. Org. Chem. 1982, 47, 1373-1378. b) Behrens, C. H.; Ko, S. Y.; Sharpless, K. B.; Walker, F. J. J. Org. Chem. 1985, 50, 5687-5696.

6. Boeck kma n, R. K., Jr .; Pr u it t, J. R. J. Am. Chem. Soc. 1989, 111, 82868288 .

7. a) Katsuki, T.; Sharpless, K. B. J. Am. Chem. Soc. 1980, 102, 5974-5976. b) Johnson, R. A.; Sharpless, K. B. "Addition Reactions with Formation of Carbon-Oxygen Bonds: (ii) Asymmetric Methods of Epoxidation," Comp. Org. Synth. 1991, 7, 389-436. c) Katsuki, T.; Martin, V. S. Org. React. 1996, 48, 1-300.

8. Hir o i, K.; Sa t o, S. Synthesis 1985, 635-638.

9. The structures of the 1-seleno-2,3-diol $\mathbf{1 9}$ and the 3-seleno-1,2-diol $\mathbf{2 0}$ were determined by high field proton NMR experiments, in which the chemical shift of the easily identifiable methylene group was at either lower field ( $\alpha$ to oxygen) or at higher field ( $\alpha$ to selenium)

10. a) de 1 a Hoz, A.; Diaz-Ortiz, A.; Mor eno, A. Chem. Soc. Rev. 2005, 34, 164-178. b) Galema, S. A. Chem. Soc. Rev. 1997, 26, 233-238. c) Mingos, M. P.; Baghurst, D. R. Chem. Soc. Rev. 1991, 20, 1-47. d) Ro s a na, M. R.; Ta o, Y.; St iegma n, A. E.; Dudley, G. B. Chem. Sci. 2012, 3, 1240-1244. e) Kappe, C. O.; Pieber, B.; Dallinger, D. Angew. Chem. Int. Ed. 2013, 52, 1088-1094.

11. The structures of the 2-seleno-1,3-diols $\mathbf{2 4}$ and the 3-seleno-1,2-diols, $\mathbf{2 5}$ were determined by high field proton NMR experiments, especially of the acetylated products, by careful matching of coupling constants and chemical shifts of the lower field protons, along with NOESY and COSY spectra. 


\section{Graphical Abstract}

To create your abstract, type over the instructions in the template box below.

Fonts or abstract dimensions should not be changed or altered.

Trapping of Payne rearrangement intermediates with arylselenide anions

Michael E. Jung* and Daniel L. Sun

Department of Chemistry and Biochemistry, University of California, Los Angeles, California 90095-1569

Arylselenide anions trap the Payne rearrangement intermediate, e.g., 18, to give selenodiols, e.g., 17 gives 19 in good yield.

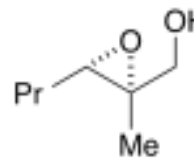

17

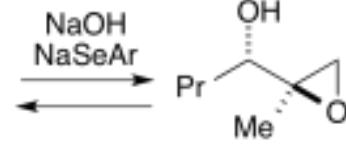

18

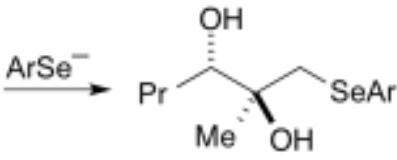

19 